\title{
Existence of a unique positive solution for a singular fractional boundary value problem
}

\section{E. T. KARIMOVand K. SADARANGANI}

\begin{abstract}
.
In the present work, we discuss the existence of a unique positive solution of a boundary value problem for a nonlinear fractional order equation with singularity. Precisely, order of equation $D_{0+}^{\alpha} u(t)=f(t, u(t))$ belongs to $(3,4]$ and $f$ has a singularity at $t=0$ and as a boundary conditions we use $u(0)=u(1)=u^{\prime}(0)=u^{\prime}(1)=0$. Using a fixed point theorem, we prove the existence of unique positive solution of the considered problem.
\end{abstract}

Acknowledgements. The present work is partially supported by the projects MTM-2016-79436-P and ULPGC 2014-04.

\section{REFERENCES}

[1] Bai, Z. and Sun, W. Existence and multiplicity of positive solutions for singular fractional boundary problems, Comput. Math. Appl., 63 (2012), No. 9, 1369-1381

[2] Caballero, J., Harjani, J. and Sadarangani, K. Positive solutions for a class of singular fractional boundary value problems, Comput. Math. Appl., 62 (2011), No. 3, 1325-1332

[3] Stanêk, S., The existence of positive solutions of singular fractional boundary value problems, Comput. Math. Appl., 62 (2011), No. 3, 1379-1388

[4] Wardowski, D., Fixed points of a new type of contractive mappings in complete metric spaces, Fixed Point Theory Appl., (2012), 2012:94, 6 pp.

[5] Xu, J., Wei, Z. and Dong, W. Uniqueness of positive solutions for a class of fractional boundary value problems, Appl. Math. Lett., 25 (2012), No. 3, 590-593

[6] Xu, X., Jiang, D. and Yuan, C. Multiple positive solutions for the boundary value problem of a nonlinear fractional differential equation, Nonl. Anal., 71 (2009), No. 10, 4676-4688

[7] Zhang, S., Positive solutions to singular boundary value problem for nonlinear fractional differential equation, Comput. Math. Appl., 59 (2010), No. 3, 1300-1309

Department of Differential Equations and Department of Mathematics

INSTITUTE OF MATHEMATICS

UZbeKistan ACADEMY OF SCIENCES AND University of LAS PALMAS DE GRAN CANARIA

TASHKENT 100125, UZBEKISTAN AND CAMPUS DE TAFIRA BAJA

35017 Las Palmas de Gran CANARIa, SPAin

E-mail address: erkinjon@gmail.com

E-mail address: ksadaranedma.ulpgc.es

Received: 06.12.2016; In revised form: 15.01.2018; Accepted: 22.01.2018

2010 Mathematics Subject Classification. 34B16.

Key words and phrases. Nonlinear fractional differential equations, singular boundary value problem, positive solution.

Corresponding author: Karimov; erkinjon@gmail.com 